\title{
FAKTOR RISIKO STROKE PADA USIA PRODUKTIF DI RUMAH SAKIT STROKE NASIONAL (RSSN) BUKIT TINGGI
}

\author{
Hendri Budi*, Indrawati Bahar, Heppi Sasmita \\ Poltekkes Kemenkes Padang \\ J1. Raya Siteba, Surau Gadang, Kec. Nanggalo, Kota Padang, \\ Sumatra Barat, 25146, Indonesia \\ *)E-mail: hendribudisalmanrosa@gmail.com
}

\begin{abstract}
ABSTRAK
Tujuan: mengetahui faktor risiko yang menyebabkan stroke hemoragik dan iskemik pada pasien usia produktif di RSSN Bukittinggi. Metode: Jenis penelitian ini deskriptif observasional dengan desain cross sectional. Penelitian dilaksanakan di RSSN Bukittinggi pada April sampai Oktober 2015. Populasinya seluruh pasien stroke yang dirawat di ruangan saraf berjumlah 2.132 pasien. Sampel berjumlah 77 orang yang memenuhi kriteria inklusi, dipilih dengan cara purposive sampling. Pengumpulan data menggunakan studi dokumentasi. Instrumen menggunakan daftar checklist tentang faktor risiko stroke yang dapat dimiliki pasien. Analisis data menggunakan statistik deskriptif, uji $t$ independent, chi square dan multivariate regresi logistik. Hasil penelitian: 58,4\% pasien stroke berjenis kelamin laki-laki; 97,4\% berumur dewasa tua (36-59 tahun), 28,6\% pekerjaan ibu rumah tangga; 68,8\% stroke iskemik, 13,2\% diantaranya berusia 21-45 tahun; 39,6\% berusia 56-59 tahun; 31,2\% stroke hemoragik, 29,2\% diantaranya berusia 21-45 tahun, 37,5\% berusia 51-55 tahun. Faktor risiko yang berhubungan dengan stroke iskemik yaitu hipertensi ( $p$ value $=0,012)$, kurang olah raga ( $p$ value $=0,008)$, dan pola makan banyak lemak ( $p$ value $=0,029)$. Faktor yang paling berpengaruh adalah hipertensi $(p$ value $=0,052)$. Faktor risiko yang berhubungan dengan stroke hemoragik yaitu hipertensi ( $p$ value $=0,016)$. Kesimpulan: Pada pasien usia produktif, stroke iskemik disebabkan oleh riwayat hipertensi, kurang olah raga dan pola makan banyak lemak, dan faktor yang paling berpengaruh yaitu riwayat kurang olah raga, sedangkan stroke hemoragik disebabkan oleh adanya riwayat hipertensi. Disarankan kepada manajemen perawatan dan perawat agar melaksanakan pendidikan kesehatan yang berfokus pada penatalaksanaan pasien hipertensi, modifikasi gaya hidup dan discharge planning terkait faktor risiko stroke kepada pasien dan keluarga.
\end{abstract}

Kata Kunci: Faktor risiko, stroke iskemik, stroke hemoragik

\section{Risk Factors of Stroke in Productive Age at National Stroke Hospital (RSSN) Bukit Tinggi ABSTRACT}

Objective: to determine the risk factors that cause hemorrhagic and ischemic strokes in productive age patients at RSSN Bukittinggi. Method: Type of research was observational descriptive with crosssectional design. The study was conducted at RSSN Bukittinggi on April to October 2015. The population was all stroke patients treated in the nerve ward totaling 2,132 patients. Samples were 77 people who met the inclusion criteria obtained by purposive sampling. Data collection used documentation study. The instrument is a checklist of stroke risk factors that a patient could have. Data analysis using descriptive statistics, independent t test and chi square test and multivariate logistic regression. Results: $58.4 \%$ of stroke patients were male, 97.4\% were elderly adults (36-59 years), 28.6\% were housewives, 68.8\% of ischemic strokes $13.2 \%$ were aged 21 -45 years, 39.6\% were 56 -59 years. 31.2\% of hemorrhagic strokes $29.2 \%$ of them aged 21-45 years, 37.5\% aged 51-55 years. Risk factors associated with ischemic stroke are hypertension (p value:0.012), lack of exercise ( $p$ value:0.008), and eating a lot of fat ( $p$ value:0.029). The most influential factor is hypertension ( $p$ value:0.052). Risk factors associated with hemorrhagic stroke are hypertension (p value:0.016). Conclusion: In patients of productive age, ischemic stroke is caused by a history of hypertension, lack of exercise and eating a lot of fat, and the 
most influential factor is a history of lack of exercise, whereas hemorrhagic stroke is caused by a history of hypertension. It is recommended to care management and nurses to carry out health education that focuses on the management of hypertensive patients, lifestyle modification and discharge planning related to stroke risk factors to patients and families.

Keywords: Risk factors, ischemic stroke, hemorrhagic stroke

\section{LATAR BELAKANG}

Stroke adalah ketidaknormalan fungsi sistem saraf pusat (SSP) yang disebabkan oleh gangguan kenormalan aliran darah ke otak. Stroke dibagi dalam dua kategori mayor yaitu stroke iskemik dan stroke hemoragik. Stroke iskemik diantaranya stroke trombolik dan embolik. Diperkirakan stroke iskemik terjadi $85 \%$ dari jumlah stroke yang ada (Brunner \& Suddarth, 2010).

Otak sangat bergantung dengan oksigen dan glukosa dalam melakukan metabolisme. Stroke iskemik terjadi karena adanya keterbatasan atau rendahnya aliran darah menuju ke bagian tertentu otak. Trombosis dan emboli merupakan dua hal yang menyebabkan terjadi hipoperfusi otak. Apabila aliran darah menurun akan terjadi gangguan fungsi neuron dan berangsur terjadi iskemia yang menetap. Pada stroke iskemik berkurangnya aliran darah ke otak menyebabkan terjadinya hipoksemia daerah regional otak dan menimbulkan reaksi-reaksi berantai yang berakhir dengan kematian sel-sel otak (Rasyid, 2007). Hal ini menyebabkan pasien akan mengalami masalah fisik, psikis dan sosial.

Masalah fisik yang terjadi pada pasien stroke yaitu adanya defisit neurologis. Defisit neurologis yang terjadi sesuai dengan lokasi dan ukuran lesi. Manifestasi klinis dari stroke antara lain gangguan motorik, gangguan komunikasi verbal, gangguan persepsi, kerusakan fungsi kognitif dan gangguan psikologis serta disfungsi kandung kemih. Sekitar 30\%-40\% penderita stroke dapat sembuh sempurna (bisa bekerja seperti biasa) asalkan penanganan terhadap mereka dilakukan dalam jangka waktu 6 jam setelah terjadinya serangan agar pasien tidak mengalami kecacatan. Sebagian besar pasien stroke datang ke rumah sakit setelah 48 jam terjadinya serangan. Hal ini menyebabkan pasien akan mengalami defisit neurologis yang cukup banyak (Brunner \& Suddarth, 2010).

Defisit neurologis yang dialami menyebabkan pasien tidak mampu melakukan peran dan fungsinya sebagai individu maupun peran dan fungsinya sebagai makhluk sosial. Hal ini akan menimbulkan dampak psikologis yang luar biasa, seperti akan mengalami harga diri rendah, putus asa, dan depresi. Selain itu serangan stroke juga dapat menyebabkan kematian [Departemen Kesehatan Republik Indonesia (Depkes RI), 2011].

Stroke merupakan penyebab kematian ketiga di dunia setelah penyakit jantung koroner dan kanker baik di negara maju maupun negara berkembang. Satu dari 10 kematian disebabkan oleh stroke. Secara global, 15 juta orang terserang stroke setiap tahunnya, satu pertiga meninggal dan sisanya mengalami kecacatan permanen (American Heart Association, 2014).

Proporsi angka kematian akibat penyakit tidak menular (PTM) di Indonesia meningkat dari 49,9\% pada tahun 2001 menjadi 59,5\% pada tahun 2007. Penyebab kematian tertinggi dari seluruh penyebab kematian yaitu stroke $(15,4 \%)$ disusul oleh hipertensi, diabetes mellitus, kanker dan penyakit paru obstruksi kronis. Di Indonesia stroke merupakan penyebab kematian terbesar di rumah sakit dan penyebab 
utama kecacatan pada kelompok usia dewasa (Rasyid, 2007).

Prevalensi stroke di Indonesia mencapai 8,3 per 1000 penduduk (Depkes, 2011). Serangan stroke lebih banyak pada lakilaki yang terjadi pada usia dibawah 45 tahun sebanyak $11,8 \%, 54,2 \%$ pada usia 45-64 tahun serta di atas usia 65 tahun sebanyak 33,5\% (Rasyid, 2007). Data Riset Kesehatan Dasar (Riskesdas) 2007 menunjukkan kematian akibat stroke pada usia 45-54 tahun di perkotaan sebesar $15,9 \%$ sedangkan di pedesaan $11,5 \%$. Hal ini menunjukkan stroke menyerang usia produktif (Depkes RI, 2011).

Rumah Sakit Stroke Nasional (RSSN) Bukittinggi merupakan rumah sakit rujukan stroke terbesar di Sumatera. Berdasarkan data yang diperoleh dari RSSN Bukititnggi pada tahun 2013, terdapat 501 pasien yang menderita stroke dengan kelompok usia 20 sampai dengan 30 tahun $(3,59 \%)$, usia $30-50$ tahun $20,76 \%$ dan usia $51-70$ tahun $52,69 \%$ dan usia $71-90$ tahun $22,95 \%$ (RSSN Bukittinggi, 2013).

Untuk itu perlu dilakukan upaya pencegahan agar kelompok usia produktif terhindar dari stroke sehingga dapat melakukan peran dan fungsinya di dalam keluarga dan di tengah-tengah masyarakat. Upaya pencegahan dapat diketahui dengan mengidentifikasi faktor risiko yang paling banyak yang menyebabkan serangan stroke.

Penggolongan faktor risiko stroke terkini didasarkan pada ada atau tidak adanya risiko tersebut ditanggulangi atau diubah. Faktor risiko yang tidak dapat diubah adalah umur, jenis kelamin, ras, faktor keturunan, dan kelainan pembuluh darah bawaan. Faktor risiko yang dapat diubah, yaitu hipertensi, diabetes mellitus, merokok, hiperkolesterolemia, obesitas, panggunaan alkohol, olahraga yang kurang, penyakit jantung, pola makan banyak lemak, penyalahgunaan narkoba, pemakaian obat kontrasepsi, dan stres (Brunner \& Suddarth, 2010).

Dengan mengetahui faktor risiko yang menyebabkan stroke pada usia produktif, maka akan dapat dilakukan upaya pencegahan primer melalui kegiatan preventif dan promotif sehingga kejadian stroke pada usia produktif dapat dicegah. Sehubungan dengan hal tersebut, maka perlu dikaji faktor risiko stroke pada pasien usia produktif melalui suatu penelitian.

\section{METODE}

Jenis penelitian ini adalah deskriptif observasional dengan menggunakan desain cross sectional, dimana faktor risiko yang menyebabkan stroke pada pasien diidentifikasi melalui status medical record pasien. Penelitian ini dilaksanakan di RSSN Bukittinggi dan dilaksanakan pada bulan Mei sampai dengan Oktober 2015. Instrumen pada penelitian ini adalah daftar checklist tentang faktor risiko stroke yang dapat dimiliki pasien. Pokok-pokok pertanyaan yang terdapat dalam instrumen diantaranya jenis stroke yang dialami, adanya riwayat asam urat, riwayat hipertensi, riwayat diabetes mellitus (DM), riwayat merokok, riwayat minum alkohol, kurang olah raga, riwayat sakit jantung, pola makan banyak berlemak, riwayat kontrasepsi hormonal dan riwayat stress yang dimiliki responden. Kuesioner penelitian ini telah dibuat oleh peneliti berdasarkan pokok pokok pertanyaan tentang faktor risiko stroke yang dapat dimiliki pasien.

Populasi dalam penelitian ini adalah seluruh pasien stroke yang dirawat di Ruangan Saraf RSSN Bukittinggi yang berjumlah 2.132 pasien. Sampel pada penelitian berjumlah 77 orang, diperoleh dengan cara purposive sampling yaitu sampel yang memenuhi kriteria inklusi yaitu pasien termasuk usia produktif yaitu antara 20 s.d 59 tahun dengan status medical record 
yang tersedia dengan lengkap pada waktu penelitian dilaksanakan. Pengumpulan data dilakukan secara studi dokumentasi terhadap status medical record pasien.

Setelah dilakukan pengumpulan data, selanjutnya dilakukan pengolahan data dan analisis data secara univariat dan bivariat. Pengolahan data menggunakan komputer. Analisis data secara univariat menggunakan statistik deskriptif dengan cara distribusi frekuensi dan persentase dari masing-masing sub variabel faktor risiko stroke. Sub variabel tersebut adalah asam urat, hipertensi, diabetes mellitus, merokok, panggunaan alkohol, kurang olahraga, penyakit jantung, pola makan banyak lemak, pemakaian obat kontrasepsi, dan stres. Analisis data secara bivariat dengan menggunakan uji $t$ independent untuk melihat perbedaan karakteristik umur responden pada pasien yang mengalami stroke iskemik dan stroke hemoragik. Uji chi square untuk melihat hubungan masingmasing variabel dengan kejadian stroke iskemik dan hemoragik serta uji multivariate regresi logistic untuk mengetahui faktor risiko yang paling berpengaruh terhadap stroke iskemik dan stroke hemoragik.

Beberapa aspek yang menjadi bahan pertimbangan etik dalam penelitian adalah kebebasan dalam mengikuti penelitian, menghormati privacy dengan menjaga kerahasiaan baik identitas maupun informasi yang diberikan. Penelitian ini dilaksanakan setelah mendapatkan izin penelitian dari RSSN Bukittinggi.

\section{HASIL}

Hasil penelitian tentang faktor risiko yang menyebabkan stroke pada pasien usia produktif di RSSN Bukittinggi ditampilkan sebagai berikut:

\section{Karakteristik Responden}

Hasil analisis karakteristik responden pada penelitian ini menggambarkan distribusi frekuensi responden berdasarkan jenis kelamin, umur, pekerjaan, dan jenis stroke yang dialami responden. Berdasarkan tabel 1 didapatkan $58,4 \%$ responden berjenis kelamin laki-laki, 97,4\% responden berumur dewasa tua, lebih banyak $(28,6 \%)$ bekerja sebagai ibu rumah tangga dan lebih dari setengah $(68,8 \%)$ responden mengalami stroke iskemik.

Berdasarkan tabel 2 didapatkan bahwa stroke iskemik lebih banyak terdapat pada responden berusia 56-59 tahun yaitu 39,6\% sedangkan stroke hemorragik lebih banyak pada responden berusia 51-55 tahun yaitu $37,5 \%$. Selain itu juga diketahui bahwa kejadian stroke iskemik pada responden yang berusia antara 21-45 tahun sebanyak $13,2 \%$, sedangkan kejadian stroke hemorragik pada responden yang berusia antara 21-45 tahun sebanyak 29,2\%. Berdasarkan tabel 3 dapat diketahui bahwa berdasarkan uji $t$ independent tidak ada perbedaan umur pasien stroke iskemik dan stroke hemoragik ( $p$ value $=0,407$ ).

Berdasarkan tabel 4 didapatkan bahwa kejadian stroke iskemik lebih banyak terdapat pada responden yang mempunyai riwayat hipertensi $(75,8)$, kemudian kurang olah raga $(74,6 \%)$ dan disusul dengan pola makan banyak lemak $(74,2 \%)$. Kejadian stroke hemoragik lebih banyak terdapat pada responden yang mempunyai riwayat hipertensi $(37,7 \%)$, kemudian disusul dengan riwayat merokok $(33,3 \%)$ dan disusul dengan pola makan banyak berlemak $(25,8 \%)$. Berdasarkan tabel 5 dapat diketahui bahwa berdasarkan uji statistic chi square ada hubungan riwayat hipertensi dengan kejadian stroke iskemik ( $p$ value $=0,012$ ), ada hubungan riwayat kurang olah raga dengan kejadian stroke iskemik ( $p$ value $=0,008$ ), dan ada hubungan riwayat pola makan banyak lemak dengan kejadian stroke iskemik ( $p$ value $=0,029)$. 
Berdasarkan tabel 6 dapat diketahui berdasarkan uji statistic chi square diperoleh hasil bahwa ada hubungan riwayat hipertensi dengan kejadian stroke hemoragik ( $p$ value $=0,016$ ). Berdasarkan hasil uji statistik chi square tersebut, maka didapatkan hanya faktor risiko hipertensi yang berhubungan dengan kejadian stroke hemoragik dengan nilai $p$ value 0,016 .

Kemudian untuk mengetahui faktor dominan yang berhubungan dengan kejadian stroke iskemik, maka ketiga faktor yang ada hubungan dengan kejadian stroke iskemik dilakukan analisis permodelan akhir stroke iskemik dengan uji multivariate regresi logistik.

Berdasarkan tabel 7 terlihat hasil pemodelan akhir stroke iskemik dengan uji multivariate regresi logistik bahwa variabel independen yang paling dominan adalah variabel faktor riwayat hipertensi dimana didapat nilai odd ratio (OR) sebesar 9,39 artinya jika pasien mempunyai riwayat hipertensi maka akan memiliki resiko sebesar 9,39 kali mengalami stroke iskemik dibandingkan dengan faktor lainnya.

Tabel 1

Distribusi Frekuensi Karakteristik Responden Di RSSN Bukittinggi Tahun 2015

\begin{tabular}{clcc}
\hline No & Karakteristik & Jumlah & Persentase (\%) \\
\hline Jenis kelamin & & \\
\hline 1 & Laki-laki & 45 & 58,4 \\
2 & Perempuan & 32 & 100 \\
\hline \multicolumn{2}{c}{ Ju m I a h } & 77 & \\
\hline Umur & & & 2,6 \\
\hline 1 & Dewasa Muda & 2 & 97,4 \\
2 & Dewasa Tua & 75 & \\
\hline Pekerjaan & & 28,5 \\
\hline 1 & Ibu rumah tangga & 22 & 13,0 \\
2 & Petani & 10 & 26,0 \\
3 & Wiraswasta & 20 & 14,3 \\
4 & PNS & 11 & 5,2 \\
5 & Pegawai Swasta & 4 & 3,9 \\
6 & TNI/POLRI & 3 & 3,9 \\
7 & Pedagang & 3 & 2,6 \\
8 & Guru & 2 & 1,3 \\
9 & Buruh & 1 & 1,3 \\
10 & Mahasiswa & 1 & 31,2 \\
\hline Jenis & Stroke & & 100 \\
\hline 1 & Stroke Iskemik & 53 & \\
2 & Stroke Hemoragik & 24 & \\
\hline & J u m I a h & 77 & \\
\hline
\end{tabular}


Tabel 2

Distribusi Frekuensi Kejadian Stroke Responden Berdasarkan Kelompok Usia Produktif Di RSSN Bukittinggi Tahun 2015

\begin{tabular}{|c|c|c|c|c|c|}
\hline \multirow{3}{*}{ No } & \multirow{3}{*}{$\begin{array}{l}\text { Kelompok Umur } \\
\text { Produktif }\end{array}$} & \multicolumn{4}{|c|}{ Jenis Stroke } \\
\hline & & \multicolumn{2}{|c|}{ Stroke Iskemik } & \multicolumn{2}{|c|}{ Stroke Hemoragik } \\
\hline & & $\begin{array}{l}\text { Frekuensi } \\
\text { (f) }\end{array}$ & $\begin{array}{c}\text { Persentase } \\
\text { (\%) }\end{array}$ & $\begin{array}{l}\text { Frekuensi } \\
\text { (f) }\end{array}$ & $\begin{array}{c}\text { Persentase } \\
(\%)\end{array}$ \\
\hline 1 & $21-25$ tahun & 1 & 1,9 & 0 & 0 \\
\hline 2 & $26-30$ tahun & 0 & 0 & 0 & 0 \\
\hline 3 & $31-35$ tahun & 0 & 0 & 1 & 4,2 \\
\hline 4 & $36-40$ tahun & 4 & 7,5 & 2 & 8,3 \\
\hline 5 & $41-45$ tahun & 2 & 3,8 & 4 & 16,7 \\
\hline 6 & $46-50$ tahun & 14 & 26,4 & 2 & 8,3 \\
\hline 7 & $51-55$ tahun & 11 & 20,8 & 9 & 37,5 \\
\hline \multirow[t]{2}{*}{8} & $56-59$ tahun & 21 & 39,6 & 6 & 25,0 \\
\hline & $\mathrm{Jumlah}$ & 53 & 100 & 24 & 100 \\
\hline
\end{tabular}

Tabel 3

Analisis Perbedaan Karakteristik Umur Responden Antara Kejadian Stroke Iskemik dengan Stroke Hemoragik Di RSSN Bukittinggi Tahun 2015 ( $n=77$ )

\begin{tabular}{clllll}
\hline Variabel & \multicolumn{1}{c}{ Jenis Stroke } & $\mathbf{n}$ & Mean & SD & p value \\
\hline \multirow{2}{*}{ Umur Responden } & Iskemik & 53 & 51,396 & 7,183 & \multirow{2}{*}{0,407} \\
\cline { 2 - 5 } & Hemoragik & 24 & 10,375 & 7,112 & \\
\hline
\end{tabular}

Tabel 4

Distribusi Frekuensi Jenis Stroke Responden Berdasarkan Faktor Risiko Di RSSN Bukittinggi Tahun 2015

\begin{tabular}{llcccc}
\hline \multirow{2}{*}{ No } & \multirow{2}{*}{ Faktor Risiko } & \multicolumn{4}{c}{ Jenis Stroke } \\
\cline { 3 - 6 } & & \multicolumn{2}{c}{ Stroke Iskemik } & \multicolumn{2}{c}{ Stroke Hemoragik } \\
\cline { 3 - 6 } & & $\begin{array}{c}\text { Frekuensi } \\
(\mathbf{f})\end{array}$ & $\begin{array}{c}\text { Persentase } \\
(\mathbf{\%})\end{array}$ & $\begin{array}{c}\text { Frekuensi } \\
(\mathbf{f})\end{array}$ & $\begin{array}{c}\text { Persentase } \\
(\mathbf{\%})\end{array}$ \\
\hline 1 & Riwayat Asam Urat & 1 & 1,9 & 1 & 4,2 \\
\hline 2 & Riwayat Hipertensi & 47 & 75,8 & 23 & 37,7 \\
\hline 3 & Riwayat DM & 12 & 22,6 & 5 & 20,8 \\
\hline 4 & Riwayat Merokok & 17 & 32,1 & 8 & 33,3 \\
\hline 5 & Riwayat Minum Alkohol & 0 & 0 & 0 & 0 \\
\hline 6 & Kurang Olah Raga & 50 & 74,6 & 16 & 24,2 \\
\hline 7 & Riwayat Jantung & 1 & 1,9 & 3 & 12,5 \\
\hline
\end{tabular}




\begin{tabular}{llcccc}
\hline & \multirow{2}{*}{ Foktor Risiko } & \multicolumn{4}{c}{ Jenis Stroke } \\
\cline { 3 - 6 } & & \multicolumn{2}{c}{ Stroke Iskemik } & \multicolumn{2}{c}{ Stroke Hemoragik } \\
\cline { 3 - 6 } & & $\begin{array}{c}\text { Frekuensi } \\
(\mathbf{f})\end{array}$ & $\begin{array}{c}\text { Persentase } \\
(\%)\end{array}$ & $\begin{array}{c}\text { Frekuensi } \\
(\mathbf{f})\end{array}$ & $\begin{array}{c}\text { Persentase } \\
(\%)\end{array}$ \\
\hline 8 & Pola Makan Banyak Berlemak & 49 & 74,2 & 17 & 25,8 \\
\hline 9 & Riwayat Kontrasepsi Hormonal & 0 & 0 & 0 & 0 \\
\hline 10 & Riwayat Stres & 6 & 11,3 & 4 & 16,7 \\
\hline & J u m I a h & 53 & 100 & 24 & 100 \\
\hline
\end{tabular}

Tabel 5

Hubungan Faktor Stroke Dengan Kejadian Stroke Iskemik Di RSSN Bukittinggi ( $\mathrm{n}=24)$

\begin{tabular}{|c|c|c|c|c|c|c|c|}
\hline \multirow{3}{*}{ Faktor Risiko } & \multicolumn{4}{|c|}{ Stroke Iskemik } & \multirow{2}{*}{\multicolumn{2}{|c|}{ Total }} & \multirow{3}{*}{$p$ value } \\
\hline & \multicolumn{2}{|c|}{ Tidak } & \multicolumn{2}{|c|}{$\mathrm{Ya}$} & & & \\
\hline & $f$ & $\%$ & $f$ & $\%$ & $f$ & $\%$ & \\
\hline \multicolumn{8}{|l|}{ Riwayat Asam Urat } \\
\hline Tidak & 23 & 30,7 & 52 & 69,3 & 75 & 100 & 0,529 \\
\hline Ya & 1 & 50,0 & 1 & 50,0 & 2 & 100 & \\
\hline \multicolumn{8}{|l|}{ Riwayat Hipertensi } \\
\hline Tidak & 9 & 60,0 & 6 & 40,0 & 15 & 100 & \\
\hline $\mathrm{Ya}$ & 15 & 24,2 & 47 & 75,8 & 62 & 100 & 0,012 \\
\hline \multicolumn{8}{|l|}{ Riwayat DM } \\
\hline Tidak & 19 & 31,7 & 41 & 68,3 & 60 & 100 & \\
\hline $\mathrm{Ya}$ & 5 & 29,4 & 12 & 70,6 & 17 & 100 & 1,000 \\
\hline \multicolumn{8}{|l|}{ Riwayat Merokok } \\
\hline Tidak & 16 & 30,8 & 36 & 69,2 & 52 & 100 & \\
\hline Ya & 8 & 32,0 & 17 & 68,0 & 26 & 100 & 1,000 \\
\hline \multicolumn{8}{|l|}{ Kurang Olah Raga } \\
\hline Tidak & 7 & 70,0 & 3 & 30,0 & 10 & 100 & \\
\hline $\mathrm{Ya}$ & 17 & 25,4 & 50 & 74,6 & 67 & 100 & 0,008 \\
\hline \multicolumn{8}{|l|}{ Riwayat Jantung } \\
\hline Tidak & 21 & 28,8 & 52 & 71,2 & 73 & 100 & \\
\hline $\mathrm{Ya}$ & 3 & 75,0 & 1 & 25,0 & 4 & 100 & 0,087 \\
\hline \multicolumn{8}{|c|}{ Riwayat Pola Makan Banyak Berlemak } \\
\hline Tidak & 7 & 63,6 & 4 & 36,4 & 11 & 100 & \\
\hline Ya & 17 & 25,8 & 49 & 74,2 & 66 & 100 & 0,029 \\
\hline \multicolumn{8}{|l|}{ Riwayat Stres } \\
\hline Tidak & 20 & 29,9 & 47 & 70,1 & 67 & 100 & \\
\hline Ya & 4 & 40,0 & 6 & 60,0 & 10 & 100 & 0,493 \\
\hline
\end{tabular}


Tabel 6

Hubungan Faktor Stroke Dengan Kejadian Stroke Hemoragik Di RSSN Bukittinggi (n=53)

\begin{tabular}{|c|c|c|c|c|c|c|c|}
\hline \multirow{3}{*}{ Faktor Risiko } & \multicolumn{4}{|c|}{ Stroke Hemoragik } & \multirow{2}{*}{\multicolumn{2}{|c|}{ Total }} & \multirow{3}{*}{$p$ value } \\
\hline & \multicolumn{2}{|c|}{ Tidak } & \multicolumn{2}{|c|}{$\mathrm{Ya}$} & & & \\
\hline & $f$ & $\%$ & $f$ & $\%$ & f & $\%$ & \\
\hline \multicolumn{8}{|l|}{ Riwayat Asam Urat } \\
\hline Tidak & 52 & 69,3 & 23 & 30,7 & 75 & 100 & 0,529 \\
\hline Ya & 1 & 50,0 & 1 & 50,0 & 2 & 100 & \\
\hline \multicolumn{8}{|l|}{ Riwayat Hipertensi } \\
\hline Tidak & 15 & 93,8 & 1 & 6,2 & 16 & 100 & 0,016 \\
\hline $\mathrm{Ya}$ & 38 & 62,3 & 23 & 37,7 & 61 & 100 & \\
\hline \multicolumn{8}{|l|}{ Riwayat DM } \\
\hline Tidak & 41 & 68,3 & 19 & 31,7 & 60 & 100 & 1,000 \\
\hline $\mathrm{Ya}$ & 12 & 70,6 & 5 & 29,4 & 17 & 100 & \\
\hline \multicolumn{8}{|l|}{ Riwayat Merokok } \\
\hline Tidak & 36 & 69,2 & 16 & 30,8 & 52 & 100 & 1,000 \\
\hline Ya & 17 & 68,8 & 8 & 32,0 & 25 & 100 & \\
\hline \multicolumn{8}{|l|}{ Kurang Olah Raga } \\
\hline Tidak & 6 & 54,5 & 5 & 45,5 & 11 & 100 & 0,303 \\
\hline $\mathrm{Ya}$ & 47 & 71,2 & 19 & 28,8 & 66 & 100 & \\
\hline \multicolumn{8}{|l|}{ Riwayat Jantung } \\
\hline Tidak & 52 & 71,2 & 21 & 71,2 & 73 & 100 & 0,087 \\
\hline $\mathrm{Ya}$ & 1 & 25,0 & 3 & 75,0 & 4 & 100 & \\
\hline \multicolumn{8}{|c|}{ Riwayat Pola Makan Banyak Berlemak } \\
\hline Tidak & 8 & 72,7 & 3 & 27,3 & 11 & 100 & 1,000 \\
\hline Ya & 45 & 68,2 & 21 & 31,8 & 66 & 100 & \\
\hline \multicolumn{8}{|l|}{ Riwayat Stres } \\
\hline Tidak & 47 & 70,1 & 20 & 29,9 & 67 & 100 & 0,493 \\
\hline $\mathrm{Ya}$ & 6 & 60,0 & 4 & 40,0 & 10 & 100 & \\
\hline
\end{tabular}

Tabel 7

Analisis Pemodelan Akhir Stroke Iskemik

\begin{tabular}{|c|c|c|c|c|}
\hline No & Variabel & B & $p$ value & OR \\
\hline 1 & Riwayat Hipertensi & 2,240 & 0,052 & 9,390 \\
\hline 2 & Riwayat kurang Olahraga & 1,671 & 0,070 & 0,188 \\
\hline 3 & Riwayat Makanan Berlemak & 0,954 & 0,398 & 2,597 \\
\hline
\end{tabular}




\section{DISKUSI}

Hasil penelitian ini membuktikan bahwa kejadian stroke iskemik dan stroke hemoragik dapat terjadi pada usia produktif. Meningkatnya penderita stroke usia muda lebih disebabkan pola hidup, terutama pola makan tinggi kolesterol. Berdasarkan pengamatan di berbagai rumah sakit, justru stroke di usia produktif sering terjadi akibat kesibukan kerja yang menyebabkan seseorang jarang olahraga, kurang tidur, dan stres berat yang juga jadi faktor penyebab (Purwaningtiyas, 2014).

Meningkatnya jumlah kasus stroke pada usia produktif menurut peneliti dapat disebabkan gaya hidup yang tidak sehat seperti pola makan yang banyak lemak kurangnya olah raga dan adanya riwayat stress sehinga memicu terjadinya hipertensi. Hal ini diperkuat dengan adanya kebiasaan masyarakat Sumatera Barat mengkonsumsi makanan yang banyak mengandung santan seperti gulai manis, kalio santan, makanan yang digoreng, dan mengandung lemak seperti usus dan jeroan sehingga dapat meningkatkan kadar kolesterol darah dan memicu terjadinya atheroskeloris dan thrombosis yang mengakibatkan berkurangnya suplai oksigen ke otak.

Life style atau gaya hidup selalu dikaitkan dengan berbagai penyakit yang menyerang usia produktif. Generasi muda sering menerapkan pola makan yang tidak sehat dengan seringnya mengkonsumsi makanan siap saji yang sarat dengan lemak dan kolesterol tapi rendah serat (Purwaningtiyas, 2014).

Hasil penelitian ini hampir sama dengan penelitian yang dilakukan oleh Purwaningtiyas (2014) yang memperoleh hasil bahwa responden pada kelompok kasus (penderita stroke) paling banyak adalah kelompok umur 40-42 tahun yaitu 19 orang $(33,3 \%)$.
Hasil penelitian ini juga hampir sama dengan Riskesdas tahun 2013 yang menyatakan bahwa kasus stroke tertinggi yang terdiagnosis tenaga kesehatan di Indonesia adalah usia 75 tahun ke atas $(43,1 \%)$ dan terendah pada kelompok usia $15-24$ tahun yaitu sebesar $0,2 \%$. Prevalensi stroke berdasarkan jenis kelamin lebih banyak laki-laki $(7,1 \%)$ dibandingkan dengan perempuan $(6,8 \%)$. Sesuai pula dengan Handayani (2013) yang menyebutkan bahwa angka kejadian serangan stroke lebih rendah pada wanita daripada laki-laki.

Hasil penelitian menunjukkan bahwa pasien stroke bekerja sebagai ibu rumah tangga yaitu 22 orang $(28,6 \%)$. Hasil ini berbeda dengan penelitian yang dilakukan oleh Rico, Suharyo \& Endang (2008) yang mendapatkan hasil bahwa berdasarkan jenis pekerjaan, pada kelompok kasus responden (pasien stroke) yang paling tinggi dengan pekerjaan pegawai swasta yaitu sebesar $42 \%$, sedangkan yang paling sedikit dengan pekerjaan pensiunan yaitu sebesar $2 \%$.

Hasil penelitian ini berbeda dengan penelitian yang dilakukan oleh Purwaningtiyas (2014) yang memperoleh hasil bahwa lebih banyak pasien stroke berjenis kelamin perempuan yaitu 39 orang $(68,4 \%), 38,6 \%$ berumur dewasa muda (19-36 tahun) dan lebih banyak pasien stroke yang bekerja sebagai wiraswasta yaitu 43,8\%. Perbedaan ini dapat disebabkan oleh karakteristik responden yang berbeda diantara dua tempat penelitian.

Pada penelitian ini ternyata tidak didapatkan perbedaan yang bermakna antara karakteristik responden yaitu jenis kelamin, umur, pekerjaan pada responden yang mengalami stroke iskemik maupun yang mengalami stroke hemoragik. Hal ini terlihat dari hasil uji tindependent pada tabel 3 bahwa tidak terdapat perbedaan yang bermakna antara umur, jenis kelamin dan pekerjaan pada responden stroke iskemik 
dan responden stroke hemoragik.

Untuk stroke iskemik dari hasil penelitian menunjukkan bahwa berdasarkan uji statistic chi square pada tabel 5 terdapat 3 faktor risiko yang mempunyai hubungan yang bermakna dengan kejadian stroke iskemik yaitu faktor riwayat hipertensi, riwayat kurang olah raga, riwayat pola makan banyak lemak dan pada tabel 7 dari ketiga faktor tersebut, faktor riwayat hipertensi merupakan faktor yang paling dominan yang menyebabkan stroke iskemik dengan nilai odd ratio (OR) sebesar 9,39 artinya jika pasien mempunyai riwayat hipertensi maka akan beresiko sebesar 9,39 kali mengalami stroke iskemik dibandingkan dengan faktor lainnya. Pada stroke hemoragik dari hasil penelitian menunjukkan bahwa berdasarkan uji statistic chi square pada tabel 6 hanya factor riwayat hipertensi yang berhubungan dengan kejadian stroke hemoragik.

Hasil penelitian ini sesuai dengan hasil penelitian Rico, Suharyo \& Endang (2008) yang menyebutkan bahwa faktor risiko yang berhubungan dengan kejadian stroke pada usia muda adalah riwayat hipertensi, riwayat keluarga dan tekanan darah sistolik. Sedangkan faktor yang tidak memiliki hubungan yang bermakna dengan kejadian stroke usia muda adalah jenis kelamin, kelainan jantung, kadar gula darah sewaktu, kadar gula darah puasa, kadar gula darah PP, total kadar kolesterol darah dan total trigliserida.

Hasil penelitian ini hampir sesuai dengan yang dilakukan oleh Sari (2012) menyatakan bahwa terdapat pengaruh yang signifikan antara hipertensi OR= 6,538 (95\% C.I $=1,720-24,856)$ dan penyakit jantung koroner OR=15,172 (95\% C.I =1,495$153,923)$ terhadap kejadian stroke iskemik pada usia produktif.

Pada penelitian didapatkan bahwa faktor hipertensi merupakan yang paling banyak menyebabkan stroke iskemik $(75,8 \%)$ dan nomor satu terbanyak pada stroke hemoragik $(37,7 \%)$. Seseorang dikatakan hipertensi bila tekanan darah sistolik lebih besar atau sama dengan $140 \mathrm{mmHg}$ atau tekanan darah sistolik sama atau lebih besar dari $90 \mathrm{mmHg}$. Makin tinggi tekanan darah makin tinggi kemungkinan terjadinya stroke, baik non hemoragik maupun hemoragik. Tekanan darah yang meningkat secara perlahan merusak dinding pembuluh darah, meningkatkan tahanan arteri dan mendorong terbentuknya bekuan darah dan aneurisme, yang semuanya mengarah pada stroke (Brunner \& Suddarth, 2010).

Seseorang menderita stroke karena memiliki perilaku yang dapat meningkatkan faktor risiko stroke. Gaya hidup yang tidak sehat seperti mengkonsumsi makanan tinggi lemak dan tinggi kolesterol, kurang aktivitas fisik, dan kurang olahraga, meningkatkan risiko terkena penyakit stroke (Aulia, 2008). Gaya hidup sering menjadi penyebab berbagai penyakit yang menyerang usia produktif, karena generasi muda sering menerapkan pola makan yang tidak sehat dengan seringnya mengkonsumsi makanan tinggi lemak dan kolesterol tapi rendah serat. Selain banyak mengkonsumsi kolesterol, mereka mengkonsumsi gula yang berlebihan sehingga akan menimbulkan kegemukan yang berakibat terjadinya penumpukan energi dalam tubuh (Purwaningtiyas, 2014).

Faktor risiko lainnya yang jumlahnya cukup besar yaitu merokok dimana terdapat $68 \%$ pasien stroke iskemik memiliki faktor risiko merokok dan $32,0 \%$ pasien stroke hemoragik memiliki faktor risiko merokok walaupun dari hasil uji statistik tidak terdapat hubungan yang bermakna antara kejadian stroke dengan merokok. Hasil penelitian ini sesuai dengan hasil penelitian Bhat, dkk (2008), yang menyimpulkan merokok merupakan faktor risiko stroke pada wanita muda. Merokok berisiko 2,6 kali terhadap kejadian stroke pada wanita muda. Merokok 
dapat meningkatkan kecenderungan selsel darah menggumpal pada dinding arteri, menurunkan jumlah HDL (High Density Lipoprotein), menurunkan kemampuan HDL dalam menyingkirkan kolesterol LDL (Low Density Lipoprotein) yang berlebihan, serta meningkatkan oksidasi lemak yang berperan dalam perkembangan atherosclerosis.

The National Stroke Association menjelaskan bahwa faktor risiko tambahan perempuan berusia di atas 30 tahun yang merokok dan mengonsumsi kontrasepsi oral dengan kandungan estrogen yang lebih tinggi memiliki resiko stroke 22 kali lebih besar daripada rata-rata (Brunner \& Suddarth, 2010).

Pada penelitian ini juga didapatkan data tentang faktor risiko lainnya yang jumlahnya cukup besar yaitu diabetes mellitus walaupun dari hasil uji chi square tidak terdapat hubungan yang bermakna antara kejadian stroke dengan diabetes mellitus. Terdapat $22,6 \%$ pasien stroke iskemik memiliki faktor risiko diabetes mellitus dan $20,8 \%$ pasien stroke hemoragik memiliki faktor risiko diabetes mellitus. Tingginya kadar gula darah dalam tubuh secara patologis berperan dalam peningkatan konsentrasi glikoprotein, yang merupakan pencetus beberapa penyakit vaskuler. Kadar glukosa darah yang tinggi pada saat stroke akan memperbesar kemungkinan meluasnya area infark karena terbentuknya asam laktat akibat metabolisme glukosa secara anaerobik yang merusak jaringan otak (Rico, Suharyo \& Endang, 2008). Selain itu DM akan menimbulkan perubahan pada sistem vaskular serta mendorong terjadinya atherosclerosis dan meningkatkan terjadinya hipertensi, kegemukan dan kenaikan lemak darah. Kombinasi hipertensi dan DM sangat menaikkan komplikasi diabetes termasuk stroke (Brunner \& Suddarth, 2010).

Pada penelitian ini juga didapatkan data bahwa ditemukan $74,6 \%$ pasien stroke iskemik memiliki faktor risiko kurang olahraga dan 24,2\% pasien stroke hemoragik memiliki faktor risiko kurang olah raga. Orang yang kurang aktif secara fisik (kurang dari tiga kali atau kurang dari 1 kali perminggu, masing-masing selama 30 menit) memiliki hampir $50 \%$ risiko peningkatan terkena stroke dibandingkan dengan yang berolah raga. Tidak berolah raga dapat mengakibatkan peningkatan tekanan darah, peningkatan berat badan serta berkaitan dengan kejadian DM, menimbulkan atherosclerosis, yang semuanya merupakan faktor risiko yang penting untuk terjadinya serangan stroke. Kegiatan fisik yang teratur dapat mengurangi terjadinya stroke (sekitar 30 menit atau lebih dari 30 menit gerakan moderate tiap hari) (Brunner \& Suddarth, 2010).

Keterbatasan pada penelitian ini yaitu masih terbatasnya jumlah responden yaitu sebesar 77 orang sehingga diharapkan penelitian ini dapat dikembangkan dengan jumlah sampel yang lebih besar.

\section{SIMPULAN}

Hasil penelitian menunjukkan sebagian besar pasien mengalami stroke iskemik. Terdapat pasien dengan usia produktif yang mengalami stroke iskemik maupun hemorragik. Terdapat pasien yang berusia antara 21-45 tahun (13,2\%) dan 56-59 tahun $(39,6 \%)$ yang mengalami stroke iskemik. Terdapat pasien yang berusia antara 21-45 tahun $(29,2 \%)$ dan $51-55$ tahun $(37,5 \%)$ yang mengalami stroke hemoragik.

Stroke iskemik lebih banyak terdapat pada pasien yang mempunyai riwayat hipertensi, kurang olah raga dan pola makan banyak lemak, sedangkan stroke hemoragik lebih banyak terdapat pada pasien yang mempunyai riwayat hipertensi, riwayat merokok dan pola makan banyak berlemak. Terdapat 3 faktor risiko yang mempunyai hubungan yang bermakna dengan kejadian 
stroke iskemik yaitu faktor riwayat hipertensi, riwayat kurang olah raga, riwayat pola makan banyak lemak dimana faktor yang paling berpengaruh yaitu riwayat kurang olah raga. Kemudian hanya faktor riwayat hipertensi mempunyai hubungan yang bermakna dengan stroke hemoragik. Berdasarkan hasil penelitian ini maka diperlukan adanya upaya kesehatan promotif dan preventif dari tenaga keperawatan untuk meningkatkan kesadaran masyarakat dalam mengontrol hipertensi yang dialami, melakukan olah raga yang rutin dan mengurangi konsumsi makanan yang banyak lemak dimana upaya tersebut dapat dilakukan melalui pendidikan kesehatan modifikasi gaya hidup dan discharge planning terkait faktor risiko stroke kepada pasien dan keluarga serta masyarakat usia produktif.

\section{DAFTAR PUSTAKA}

American Heart Association. (2014). Heart disease and stroke statistics. Retrieved from: http://circ.ahajournals. org/content/early/2013/12/18/01. cir.0000441139.02102.80

Aulia. (2008). Gaya Hidup dan Penyakit Modern. Yogyakarta: Kanisius.

Badan Penelitian dan Pengembangan Kesehatan Kementerian Kesehatan RI. (2013). Riset Kesehatan Dasar, Riskesdas 2013. Retrieved from http:// www.depkes.go.id/resources/ download/ general/Hasil\%20 Riskesdas \%202013. pdf

Bhat VM, Cole JW, Sorkin JD, Wozniak MA, Malarcher AM, Giles WH, Stern BJ, Kittner SJ. (2008). Dose Response Relationship Between Cigarette Smoking and Risk of Ischemic Stroke Young Women. Journal of the American Stroke Association, 39: 2439-2443.
Brunner, L.S \& Suddarth, D.S. (2010). Brunner \& suddarth's texbook of medical-surgical nursing. (12 th ed). Philadelphia: Lippincott and Wilkins. Departemen Kesehatan Republik Indonesia. (2011). Standar Pelayanan Unit Stroke. Jakarta: Depkes RI.

Handayani. (2013). Angka Kejadian Serangan Stroke pada Wanita Lebih Rendah Daripada Laki-laki. Jurnal Keperawatan Medical Bedah, 1(1): 20.

Purwaningtiyas. (2014). Hubungan antara Gaya Hidup dengan Kejadian Stroke Pada Usia Muda di RSUD Dr. Moewardi Surakarta. Retrieved from: http://eprints.ums. ac.id/32390/2/BAB\%20I.pdf) pada tanggal 20 Oktober 2015.

Rasyid. (2007). Unit Stroke. Manajemen Stroke Secara Komprehensif. Jakarta: Balai Penerbit Fakultas Kedokteran Universitas Indonesia.

Rico, J.S., Suharyo, H., Endang, K., (2008). Faktor-Faktor yang Mempengaruhi Kejadian Stroke pada Usia Muda Kurang dari 40 Tahun. Jurnal Epidemiologi: 1-13.

RSSN Bukittinggi. (2013). Medical Record Jumlah Kasus Stroke. Bukittinggi: RSSN Bukittinggi.

Sari K. D. (2012). Faktor Risiko Kejadian Stroke Iskemik Pada Usia Produktif. Retrieved from http://adln.lib.unair. ac.id/files/disk1/490/gdlhub-gdl-s12012-saridyanka-24467-fkm-51---k. pdf. 